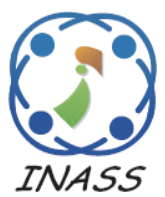

\title{
The Fuzzy Tracking Control of Output vector of Double Fed Induction Generator DFIG via T-S Fuzzy Model
}

\author{
Fouad Abdelmalki $^{1 *} \quad$ Najat Ouaaline $^{1}$ \\ ${ }^{1}$ Laboratory of Engineering, Industrial Management and Innovation Faculty of sciences and technology, \\ Hassan first university, Morocco \\ * Corresponding author’s Email: f.abdelmalki@ gmail.com
}

\begin{abstract}
The purpose of this paper is to ensure a tracking control of output state especially the active and reactive powers of doubly fed induction generator (DFIG) by using the approach of Parallel Distributed Compensation (PDC) of the fuzzy control type Takagie-Sugeno (T-S) which determines the control laws containing fuzzy tracking and return state. This tracking has been built to converge the output vectors of the DFIG to a desired state. In this work, the quadratic function of lyaponov and a linear matrix inequality (LMI) are used to obtain the gains of the tracking control and the controller.The simulations results of law control based on the tracking and controller gains allow the active and reactive powers obtained must follow the reference proposed.
\end{abstract}

Keywords: Fuzzy model, Nonlinear system, Takagie-Sugeno (T-S), DFIG, PDC, LMI, Lyapunov, Quadratic stability, Tracking control, Matlab LMI toolbox.

\section{Introduction}

The doubly fed induction machine (DFIM) has been the subject of much research mainly in industry such as generator DFIG for wind energy application $[1,2]$ and motor for ventilation systems and pumps, since it features simple structure, high-energy efficiency, reliable operation and can operate variable speed.

The dynamic model of the DFIG is not linear and that some states cannot be measured due to the lack of sensors which causes difficulties to control and know the evolution of this nonlinear system [3].

A lot of researches have been done on the modeling and control of DFIG [4-6] especially by the fuzzy model proposed by the approach TakagiSugeno (T-S) [7, 8] and the Parallel Distributed Compensation (PDC) [9].

The Takagi-Sugeno (TS) fuzzy modeling use the fuzzy IF-THEN rules for representing a local inputoutput relations of a different class of non-linear systems model [7]. The objective is to represent the local dynamics of each rule by a linear system model.
For assuring the global stability and tracking control of DFIG by the Takagi-Sugeno fuzzy model, we use a quadratic Lyapunov function to all subsystems founded by the variable transformation in to linear matrix inequalities LMIs [10, 11]. We obtain the controller and tracking gains for local fuzzy models by using the powerful computational Matlab LMI Toolbox.

The tracking control has be seen in various industrial system [12, 13], the objective of this control is to design a tracking controller and to converge the output to the desired reference model without a tracking error. Compared with stability control design and stabilization problems, the tracking control problem is more difficult especially for nonlinear systems.

In this present work, the approach based on fuzzy control Takagi- Sugeno is presented with Parallel Distributed Compensation (PDC) technique and is proposed to improve the performance of current tracking control and stability for dynamic model of nonlinear system the doubly fed Induction Generator (DFIG). 
The main advantages of this control strategy over others is to improve the performance of DFIG by dimining the response time of the convergence of active and reactive powers to a desired value.

This paper is structured as follows. In Section II, the dynamic state-space model of doubly fed induction generator and study of T-S fuzzy modelling with Fuzzy state tracking are presented and a description of LMI-based design procedures, finally we applicate the fuzzy TS method to the dynamic model of DFIG with the results obtained and simulation.

\section{Takagie - Sugeno}

\subsection{Model Takagie Sugeno}

The state space of the Double Feed Induction Generator DFIG dynamics model [8-11] is expressed $\mathrm{b}$ following Eq. (1):

$$
\left\{\begin{array}{l}
x(t)=A x(t)+B u(t) \\
y(t)=C x(t)
\end{array}\right.
$$

With

$$
\left\{\begin{array}{l}
x(t)=\left[I_{s d}, I_{s q}, I_{r d}, I_{r q}\right]^{T} \\
u(t)=\left[V_{r d}, V_{r q}, V_{s d}, V_{s q}\right]^{T} \\
y(t)=\left[P_{s}, Q_{s}\right]^{T}
\end{array}\right.
$$

and

$$
A=\left[\begin{array}{cccc}
\frac{-R_{s}}{\sigma L_{s}} & p\left(\omega_{s}+\frac{M^{2}}{\sigma L_{s} L_{r}} \omega_{r}\right) & \frac{R_{r} M}{\sigma L_{s} L_{r}} & \frac{p M}{\sigma L_{s}} \omega_{r} \\
-p\left(\omega_{s}+\frac{M^{2}}{\sigma L_{s} L_{r}} \omega_{r}\right) & \frac{-R_{s}}{\sigma L_{s}} & \frac{-p M}{\sigma L_{s}} \omega_{r} & \frac{R_{r} M}{\sigma L_{s} L_{r}} \\
\frac{R_{s} M}{\sigma L_{s} L_{r}} & \frac{-p M}{\sigma L_{s}} \omega_{r} & \frac{-R_{r}}{\sigma L_{r}} & p\left(\omega_{s}-\frac{\omega_{r}}{\sigma}\right) \\
\frac{p M}{\sigma L_{r}} \omega_{r} & \frac{R_{s} M}{\sigma L_{s} L_{r}} & -p\left(\omega_{s}-\frac{\omega_{r}}{\sigma}\right) & \frac{-R_{r}}{\sigma L_{r}}
\end{array}\right]
$$$$
B=\left[\begin{array}{cccc}
-\frac{M}{\sigma L_{s} L_{r}} & 0 & \frac{1}{\sigma L_{s}} & 0 \\
0 & -\frac{M}{\sigma L_{s} L_{r}} & 0 & \frac{1}{\sigma L_{s}} \\
\frac{1}{\sigma L_{r}} & 0 & -\frac{M}{\sigma L_{s} L_{r}} & 0 \\
0 & \frac{1}{\sigma L_{r}} & 0 & -\frac{M}{\sigma L_{s} L_{r}}
\end{array}\right]
$$

$$
C=\left[\begin{array}{cccc}
0 & 0 & 0 & -\frac{M V_{s}}{L_{s}} \\
0 & 0 & \left(\frac{V_{s}^{2}}{w_{s} L_{s}} \frac{1}{I_{r d}}-\frac{M V_{s}}{L_{s}}\right) & 0
\end{array}\right]
$$

Where

$L_{s}, L_{r}, M \quad$ : Stator, Rotor and Mutual inductance.

$R_{\mathrm{S}}, R_{r} \quad:$ Stator and Rotor resistances.

$\omega_{s}, \omega_{r} \quad:$ Stator and Rotor speed.

$I_{s q}, I_{r q} \quad:$ Stator and Rotor currents in axis q.

$I_{s d}, I_{r d} \quad:$ Stator and Rotor currents in axis d.

$x(t), u(t) \quad:$ The state system and control vector

$L_{i} \quad:$ The gains of the fuzzy observer

$K_{i} \quad:$ The gains of the fuzzy regulator.

$r \quad:$ The number of local models.

$p \quad:$ : The Number of pole.

Vs : Stator voltage magnitude.

A Takagi-Sugeno fuzzy model for a dynamic system consists of a finite set of fuzzy IF ... THEN rules expressed as follow:

Model rule i:

If $\mathrm{z}_{1}(\mathrm{t})$ is $\mathrm{F}_{1}^{\mathrm{i}}\left(\left(\mathrm{z}_{1}(\mathrm{t})\right)\right.$ and $\ldots$ and $\mathrm{z}_{\mathrm{p}}(\mathrm{t})$ is $\mathrm{F}_{\mathrm{p}}^{\mathrm{i}}\left(\left(\mathrm{z}_{1}(\mathrm{t})\right)\right.$ THEN

$$
\left\{\begin{array}{l}
\dot{x}(t)=\sum_{i=1}^{r} h_{i}(z(t))\left(A_{i} x(t)+B_{i} u(t)\right) \\
y(t)=\sum_{i=1}^{r} h_{i}(z(t))\left(C_{i} x(t)\right)
\end{array}\right.
$$

Before $F_{1}^{i}(j=1,2 \ldots p)$ the fuzzy membership function associated with the $\mathrm{i}^{\text {th }}$ rule and $\mathrm{j}^{\text {th }}$ parameter component $\mathrm{z}_{1}(\mathrm{t}) \ldots \mathrm{z}_{\mathrm{p}}(\mathrm{t})$ are known premise variable. Where $h_{i}(z(t))$ is the normalized weight for each rule.

i.e.,

$$
\left\{\begin{array}{l}
\sum_{i=1}^{r} h_{i}(z(t))=1 \\
h_{i}(z(t)) \geq 0
\end{array}\right.
$$




$$
h_{i}(z(t))=\frac{w_{i}(z(t))}{\sum_{i=1}^{r} w_{i}(z(t))}
$$

and

$$
w_{i}(z(t))=\prod_{j=1}^{p} F_{j}^{i}\left(z_{j}(t)\right)
$$

\subsection{Tracking control}

For each rule of a Takagie-Sugeno model, we use the concept of Parallel Distributed Compensation (PDC) to design fuzzy controllers to stabilize fuzzy system in the Eq. (3).

The Stability analyse is based on the quadratic Lyapunov stability such as the following definition:

\section{Definition 1:}

The system in Eq. (1) is said to be quadratic ally stable if there exists a quadratic function:

$$
V(x(t))=x^{T}(t) P x(t)
$$

With $V(0)=0$,

Satisfying the following conditions:

$$
\begin{aligned}
& V(x(t))>0, \forall x(t) \neq 0 \Leftrightarrow P>0 . \\
& \dot{V}(x(t))<0, \forall x(t) \neq 0 .
\end{aligned}
$$

If $V$ exists, it is called a Lyapunov function.

The objective of fuzzy tracking control is to achieve

$$
\lim _{t \rightarrow \infty} x(t)-x_{d}(t) \rightarrow 0
$$

By applying fuzzy control law u (t) [11], which is written in the following form:

Controller Rule i: THEN

If $\mathrm{z}_{1}(\mathrm{t})$ is $\mathrm{F}_{1}{ }^{\mathrm{i}}\left(\mathrm{z}_{1}(\mathrm{t})\right)$ and $\ldots$ and $\mathrm{z}_{\mathrm{p}}(\mathrm{t})$ is $\mathrm{F}_{\mathrm{p}}{ }^{\mathrm{i}}\left(\mathrm{z}_{1}(\mathrm{t})\right)$

$$
u(t)=\sum_{i=1}^{r} h_{i}(z(t))\left(-K_{i} x(t)+N_{i} x_{d}(t)\right)
$$

Where $x_{d}(t)$ : is the desired state vector.

$$
x_{d}(t)=\left[\begin{array}{llll}
I_{s d}^{r e f} & I_{s q}^{r e f} & I_{r d}^{r e f} & I_{r q}^{r e f}
\end{array}\right]^{T}
$$

The closed-loop model of Eq. (3) with the global control law Eq. (11) is represented as follows [11]:

$$
\left\{\begin{array}{l}
\dot{x}(t)=\sum_{i=1}^{r} \sum_{j=1}^{r} h_{i}(z(t)) h_{j}(z(t))\left(\left[\begin{array}{ll}
G_{i j} & H_{i j}
\end{array}\right]\left[\begin{array}{c}
x(t) \\
x_{d}(t)
\end{array}\right]\right) \\
y(t)=\sum_{i=1}^{r} h_{i}(z(t)) C_{i} x(t)
\end{array}\right.
$$

With

$$
\left\{\begin{array}{c}
G_{i j}=A_{i}-B_{i} K_{j} \\
H_{i j}=B_{i} N_{j}
\end{array}\right.
$$

We consider that $e(t)$ is the function error which is the difference between the state vector $x(t)$ of $\mathrm{T}$ $S$ fuzzy model Eq. (13) and the desired state vector $x_{d}(t)$, supposed constant, as:

$$
e(t)=x(t)-x_{d}(t)
$$

Combining the Eq. (13) and Eq. (15), the error dynamics

$e(t)$ Can be written as:

$$
\dot{e}(t)=\sum_{i=1}^{r} \sum_{j=1}^{r} h_{i}(z(t)) h_{j}(z(t))\left(\left[\begin{array}{ll}
G_{i j} & Z_{i j}
\end{array}\right]\left[\begin{array}{c}
e(t) \\
x_{d}(t)
\end{array}\right]\right)
$$

With

$$
Z_{i j}=G_{i j}+H_{i j}
$$

The error dynamics in Eq. (16) can be represented as follows:

$$
\begin{aligned}
\dot{e}(t)= & \sum_{i=1}^{r} h_{i}(z(t))^{2}\left(\left[\begin{array}{ll}
G_{i j} & Z_{i j}
\end{array}\right]\left[\begin{array}{c}
e(t) \\
x_{d}(t)
\end{array}\right]\right)+2 \sum_{i<j}^{r} h_{i}(z(t)) \\
& h_{j}(z(t))\left(\left[\begin{array}{ll}
\frac{G_{i j}+G_{j i}}{2} & \frac{Z_{i j}+Z_{j i}}{2}
\end{array}\right]\left[\begin{array}{c}
e(t) \\
x_{d}(t)
\end{array}\right]\right)
\end{aligned}
$$

Using the definition 1 in equation Eq. (18), we obtain:

$$
V\left(e(t)=e^{T}(t) P e(t)>0\right.
$$




$$
\begin{aligned}
\dot{V}(e(t))= & {\left[\begin{array}{l}
e(t) \\
x_{d}(t)
\end{array}\right]^{T}\left(\sum_{i=1}^{r} h_{i}(t)^{2} \Upsilon_{i i}+2 \sum_{i<j}^{r} h_{i}(t) h_{j}(t)\right.} \\
& \left.\left(\frac{\Upsilon_{i j}+\Upsilon_{j i}}{2}\right)\right)\left[\begin{array}{l}
e(t) \\
x_{d}(t)
\end{array}\right]<0
\end{aligned}
$$

With

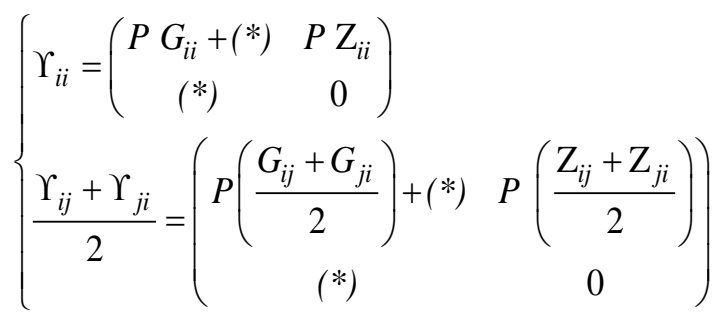

The equilibrium of the system described by Eq. (18) is asymptotically stable in the large if there exists a common positive definite matrix $\mathrm{P}$ such as these two conditions:

$$
\begin{aligned}
& \Upsilon_{i i}<0 \\
& \Upsilon_{i j}+\Upsilon_{j i}<0, \quad 1<i<j<r
\end{aligned}
$$

The conditions Eq. (22) and Eq. (23) can be represented as Eq. (24) and Eq. (25), respectively as:

$$
\begin{aligned}
& \left(\begin{array}{cc}
P G_{i i}+(*) & P Z_{i i} \\
(*) & -P
\end{array}\right)+\left(\left[\begin{array}{l}
0 \\
P
\end{array}\right] P^{-1}\left[\begin{array}{ll}
0 & P
\end{array}\right]\right)<0 \\
& \left(\begin{array}{cc}
P\left(\frac{G_{i j}+G_{j i}}{2}\right)+(*) & P\left(\frac{Z_{i j}+Z_{j i}}{2}\right) \\
(*) & -P
\end{array}\right) \\
& +\left(\left[\begin{array}{l}
0 \\
P
\end{array}\right] P^{-1}\left[\begin{array}{ll}
0 & P
\end{array}\right]\right)<0
\end{aligned}
$$

While applying to Eq. (24) and Eq. (25) the Schur's Lemma, we obtain the following equations Eq. (26) and Eq. (27), respectively as:

$$
\left(\begin{array}{ccc}
P G_{i i}+(*) & P Z_{i i} & 0 \\
(*) & -P & P \\
(*) & (*) & -P
\end{array}\right)<0
$$

For $(i=1,2,3, \ldots, r)$

$$
\left(\begin{array}{ccc}
P\left(\frac{G_{i j}+G_{j i}}{2}\right)+(*) & P\left(\frac{Z_{i j}+Z_{j i}}{2}\right) & 0 \\
(*) & -P & P \\
(*) & (*) & -P
\end{array}\right) \leq 0
$$

For $(1 \leq i<j \leq r)$

\subsection{Linear matrix inequality (LMI)}

The LMI conditions are used to find the feedback gains $\mathrm{Ki}$ and the tracking gains $\mathrm{Ni}$. In order to simplify the resolution of the LMIs, we consider the variables change by introducing matrices $\mathrm{X}, \mathrm{U}$ and $\mathrm{V}$ with appropriate dimensions:

$$
\left\{\begin{array}{l}
X=P^{-1} \\
U_{i}=K_{i} X \\
V_{i}=N_{i} X
\end{array}\right.
$$

The Conditions in Eq. (26) and Eq. (27) can be easily transformed into LMIs as follows:

$$
\left(\begin{array}{ccc}
A_{i} X-B_{i} U_{i}+(*) & \mathrm{A}_{i} X-B_{i} U_{i}+B_{i} V_{i} & 0 \\
(*) & -X & X \\
(*) & (*) & -X
\end{array}\right)<0
$$

For $(i=1,2,3, \ldots, r)$

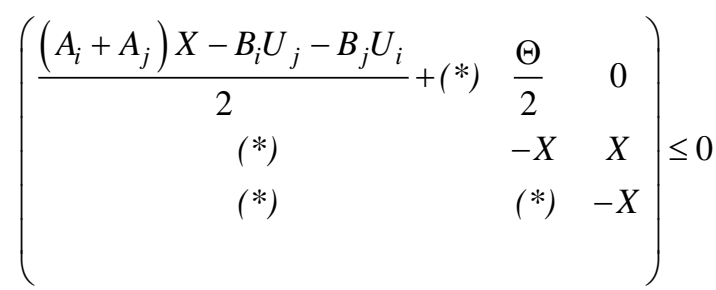

For $(1 \leq i<j \leq r)$

With

$$
\Theta=\left(A_{i}+A_{j}\right) X-B_{i} U_{j}-B_{j} U_{i}+B_{i} V_{j}+B_{j} V_{i}
$$

\section{Simulation results}

The proposed approach in this work will be used for calculating the control laws of the three-phase 1.5 Mw Doubly fed induction Generator having the following characteristics as shown in table 1: 
Table 1. Doubly fed induction Generator 1.5 MW (DFIG)

\begin{tabular}{|c|c|}
\hline \multicolumn{2}{|c|}{ Parameters } \\
\hline$R s$ & Units and values \\
\hline$R r$ & $0.026 \mathrm{Ohm}$ \\
\hline $\mathrm{Ls}$ & $87 \mu \mathrm{H}$ \\
\hline $\mathrm{Lr}$ & $87 \mu \mathrm{H}$ \\
\hline $\mathrm{M}$ & $2.5 \mu \mathrm{H}$ \\
\hline $\mathrm{Vs}$ & $690 \mathrm{~V}$ \\
\hline $\mathrm{P}$ & 2 \\
\hline
\end{tabular}

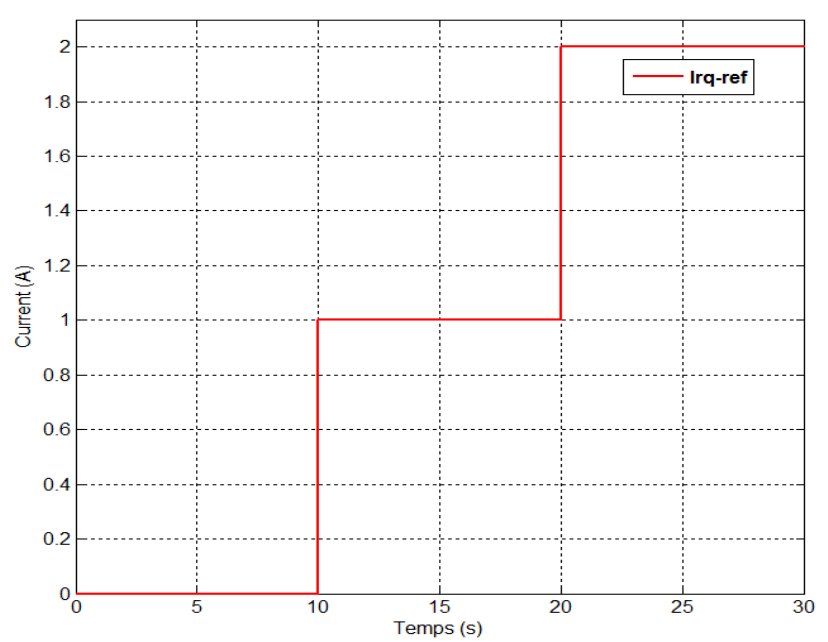

Figure.1 Simulation results of Irq-ref

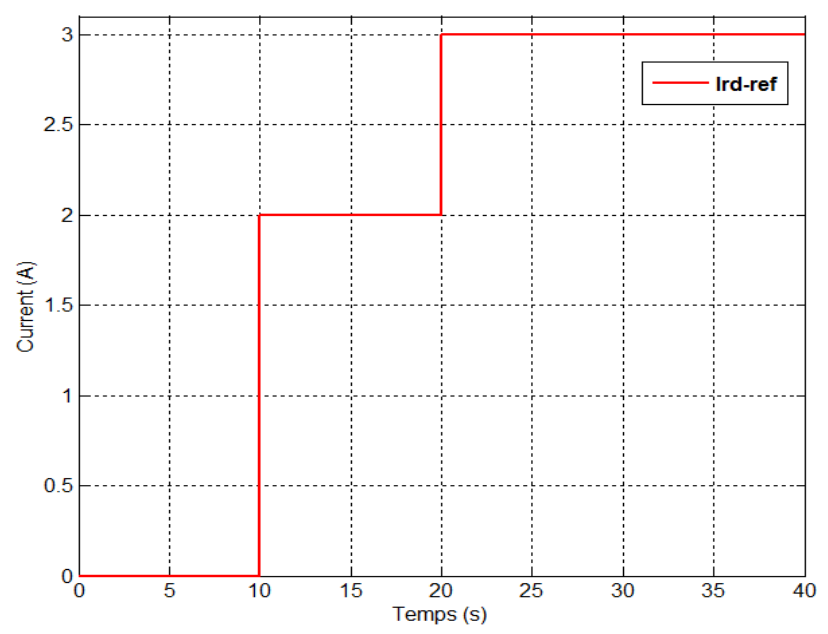

Figure.2 Simulation results of Ird_ref

As results, the simulations results obtained in terms of active and reactive power (Ps and Qs) must follow the results of the desired reference ones which are linked with the currents Irq and Ird by Eq. (1). The Figures 1 and 2 represent the proposed results the reference current. These results give us the best method to know exactly the good performances of the active and reactive power.

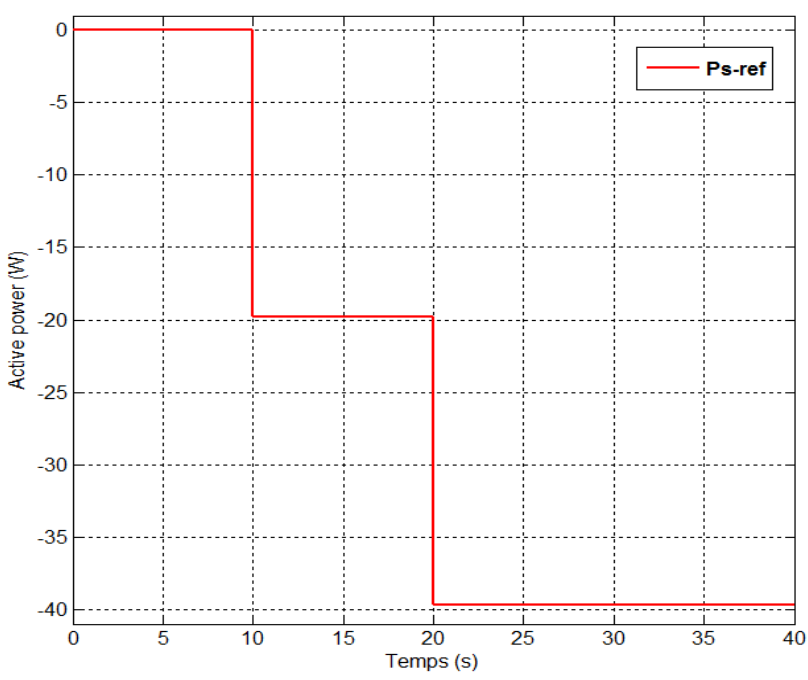

Figure.3 Simulation results of active power Ps-ref

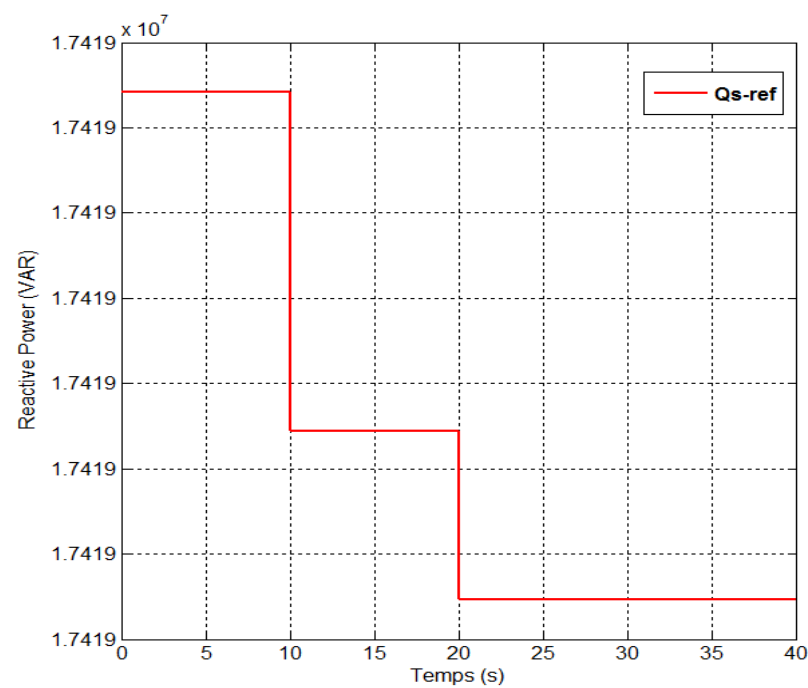

Figure.4 Simulation results of active power Ps-ref

It is observed by the Figs. 1 and 2 of the reference currents Irq and Ird, respectively, that we have the three different cases of the each current function operating in three ranges of responding time.

As mentioned above that the reference active and reactive power, and the reference currents are linked by Eq. (1). So, the results of these powers are represented in the following Figs. 3 and 4.

As we can see from the Figs. 5 and 6 , it is well observed that the results of the active and reactive power fed by the stator of the MADA follow the proposed results of the reference power for the three ranges of the responding time, Finally, we conclude that the current Irq doing the tracking control of the active power, and the direct Irq component doing the tracking control of the reactive power.

Using the LMI approach and the conditions of quadratic stability for calculate the feedback control and the tracking control gains of the fuzzy control law Eq. (11) gives the followings result: 


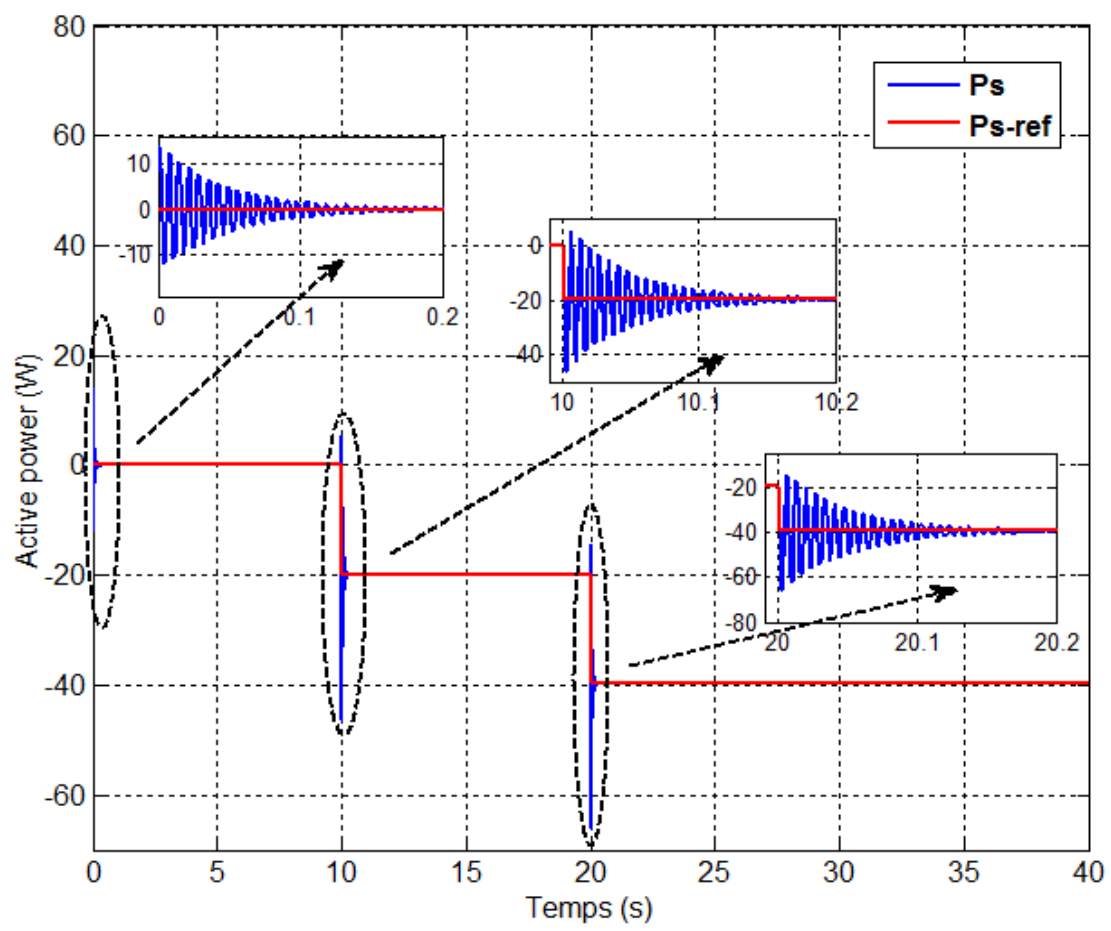

Figure.5 Simulation results of active power Ps and Ps-ref

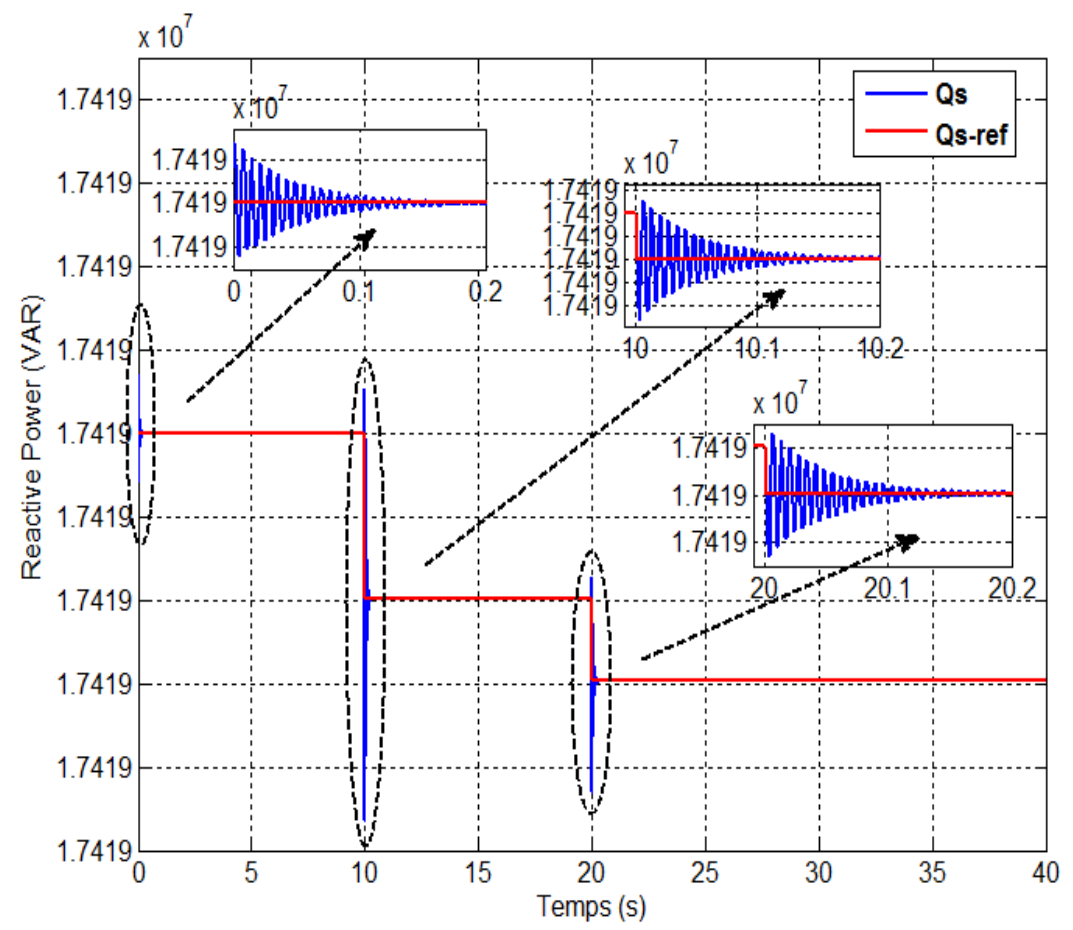

Figure.6 Simulation results of active power Qs and Qs-ref

The quadratic Lyapunov matrix P:

$$
P=\left[\begin{array}{cccc}
0,0263 & 3,532 \mathrm{e}-10 & 1,766 \mathrm{e}-08 & 8,125 \mathrm{e}-09 \\
3,532 \mathrm{e}-10 & 0,0263 & 3,290 \mathrm{e}-09 & 1,512 \mathrm{e}-08 \\
1,766 \mathrm{e}-08 & 3,290 \mathrm{e}-09 & 0,0263 & 4,520 \mathrm{e}-10 \\
8,125 \mathrm{e}-09 & 1,512 \mathrm{e}-08 & 4,520 \mathrm{e}-10 & 0,0263
\end{array}\right]
$$

Gains value $\mathrm{Ki}$ :

$$
K 1=\left[\begin{array}{llll}
-15,288 & 814,41 & -346,53 & 6993,5 \\
-886,55 & -15,337 & -7087,8 & -351,09 \\
-50,355 & 2751 & -0,5162 & 26,634 \\
-2786,9 & -50,973 & -319,90 & -14,689
\end{array}\right]
$$




$$
\begin{gathered}
K 2=\left[\begin{array}{cccc}
-15,292 & 605,81 & -346,52 & 14614 \\
-613,78 & -15,3691 & -14806 & -351,08 \\
-50,355 & 1882,8 & -0,5157 & 16,878 \\
-1907,5 & -50,974 & -613,77 & -14,685
\end{array}\right] \\
K 3=\left[\begin{array}{cccc}
-15,294 & 605,81 & -346,52 & 14614 \\
-613,78 & -15,444 & -14806 & -351,08 \\
-50,355 & 1882,8 & -0,5154 & 16,879 \\
-1907,5 & -50,977 & -613,78 & -14,675
\end{array}\right] \\
K 4= \\
-\left[\begin{array}{cccc}
-15,290 & 814,41 & -346,53 & 6993,5 \\
-886,55 & -15,379 & -7087,8 & -351,08 \\
-50,355 & 2751 & -0,5159 & 26,634 \\
-2786,9 & -50,974 & -319,90 & -14,684
\end{array}\right]
\end{gathered}
$$

Gains value Ni:

$$
\begin{aligned}
N 1 & =\left[\begin{array}{cccc}
1,8661 & -819 & 23,221 & -6996,6 \\
888,95 & 2,0417 & 7086,1 & 23,520 \\
2,9976 & -2749,9 & -0,0893 & -7,1239 \\
2785,8 & 3,0800 & 285,27 & 0,8396
\end{array}\right] \\
N 3 & =\left[\begin{array}{cccc}
1,8600 & -605,81 & 23,221 & -14614 \\
613,78 & 1,9348 & 14806 & 23,525 \\
2,9976 & -1882,7 & -0,0885 & -16,879 \\
1907,5 & 3,0756 & 613,78 & 0,8534
\end{array}\right] \\
N 2 & =\left[\begin{array}{cccc}
1,8622 & -605,81 & 23,221 & -14614 \\
613,77 & 2,0105 & 14806 & 23,521 \\
2,9976 & -1882,7 & -0,0888 & -16,879 \\
1907,5 & 3,0788 & 613,78 & 0,84362
\end{array}\right] \\
N 4 & =\left[\begin{array}{cccc}
1,8639 & -819,00 & 23,221 & -6996,6 \\
888,95 & 2,0006 & 7086,1 & 23,522 \\
2,9976 & -2749,9 & -0,0890 & -7,1241 \\
2785,8 & 3,0783 & 285,27 & 0,8449
\end{array}\right]
\end{aligned}
$$

Comparing our result of the active and reactive powers of DFIG 1.5 MW showing in Figures 5 and 6, respectively, by another obtained by method A Fuzzy Sliding Mode [5]. It's noted that the response time is more important than one referenced in [5], following Table 2 shows the comparison between the two methods:

Notation:

$$
A+(*) \rightarrow A+A^{T}
$$

Table 2. The comparison

\begin{tabular}{|c|c|c|}
\hline & $\begin{array}{c}\text { A Fuzzy } \\
\text { Takagie-Sugeno } \\
\text { method }\end{array}$ & $\begin{array}{c}\text { A Fuzzy Sliding } \\
\text { Mode method }\end{array}$ \\
\hline $\begin{array}{c}\text { Response } \\
\text { time (sec) }\end{array}$ & $0.2<\mathrm{t}<0.25$ & $0.4<\mathrm{t}<0.6$ \\
\hline
\end{tabular}

$$
\left(\begin{array}{cc}
A & B \\
(*) & C
\end{array}\right) \rightarrow\left(\begin{array}{cc}
A & B \\
B^{T} & C
\end{array}\right)
$$

\section{Conclusion}

In this work, a fuzzy Takagie-Sugeno control based on parallel distributed compensation PDC approach of output vector state of DFIG is studied and developed. Firstly, the nonlinear model of DFIG is transformed into a T-S fuzzy representation. After that, the approach PDC have been used to construct the LMI based design procedures for fuzzy controller. Secondly, the stability conditions are expressed in terms of Linear Matrix Inequalities LMI's. Finally, a design algorithm of fuzzy control system containing fuzzy regulator and fuzzy tracking is obtained. The simulation results are provided to improve the time response of obtained powers compared to the others researches.

Future work will focus on using of the proposed method in this work in order to apply in the system which contains wind turbine with DFIG for maximize the production of electrical energy and use of other types of controllers, such as $\mathrm{H}$ infinity.

\section{References}

[1] H. Polinder, F. Van der Pijl, G. De Vilder, and P. Tavner, "Comparison of direct-drive and geared generator concepts for wind turbines", IEEE Trans. Energy Convers., Vol. 21, No. 3, pp. 725733, 2006.

[2] A. Naamane and N. Msirdi, "Doubly Feed Induction Generator Control for an Urban Wind Turbine", International Renewable Energy Congress IREC, pp. 208-214, 2010.

[3] J. Ekanayake, L. Holdsworth, X. Wu, and N. Jenkins, "Dynamic modelling of doubly fed induction generator wind turbines", IEEE transactions on power systems, Vol. 18, No 2, p. 803-809, 2003.

[4] F.Abdelmalki and N. Ouaaline, "TS Fuzzy observer and controller of Doubly-Fed Induction Generator", International Journal of Power Electronics and Drive Systems, Vol.7, No.3, pp. 617-624, 2016. 
[5] O. Belounis and H. Labar, "Fuzzy Sliding Mode Controller of DFIG for Wind Energy Conversion", International Journal of Intelligent Engineering and Systems, Vol.10, No.3, pp. 163-172, 2017.

[6] M. Nadour, A. Essadki, and T. Nasser, "Comparative Analysis between PI \& Backstepping Control Strategies of DFIG Driven by Wind Turbine", International Journal of Renewable Energy Research, Vol. 7, No. 3, pp. 1307-1316, 2017.

[7] T. Takagi and M. Sugeno, "Fuzzy identification of systems and its applications to modeling and control", IEEE Transactions on Systems, Man and Cybernetics, Vol. 1, No. 1, p. 116-132, 1985 C. J. Lopez-Toribio and R. J. Patton, "TakagiSugeno fuzzy fault tolerant control for a nonlinear system," In: Proc. of the 38th IEEE Conference on Decision and Control, pp. 43684373, 1999.

[8] K. Tanaka and M. Sugeno, "Stability analysis and design of fuzzy control systems", Fuzzy Sets Syst., Vol. 45, No.2, pp. 135-156, 1992.

[9] J. Park, J. Kim, and D. Park, "LMI-based design of stabilizing fuzzy controllers for nonlinear systems described by Takagi-Sugeno fuzzy model", Fuzzy Sets Syst., Vol.122, pp.73-82, 2001.

[10] A. Abdelkrim, C. GhorbeL, and M. BENREJEB, "LMI-based tracking control for takagi-sugeno fuzzy model", International Journal of Control \& Automation, Vol. 3, No 2. 2010.

[11] S. Tong, L. Zhang, and Y. Li," Observed-based adaptive fuzzy decentralized tracking control for switched uncertain nonlinear large-scale systems with dead zones", IEEE Transactions on Systems, Man, and Cybernetics: Systems, Vol. 46, No 1, p. 37-47, 2016.

[12] H. Li, L. Wang, H. Du, and A. Boulkroune", Adaptive fuzzy backstepping tracking control for strict-feedback systems with input delay", IEEE Transactions on Fuzzy Systems, Vol. 25, No 3, p. 642-652, 2017. 